\title{
The link between stress disorders and autonomic dysfunction in muscular dystrophy
}

\author{
Rasna Sabharwal* \\ Department of Internal Medicine, University of lowa Carver College of Medicine, lowa City, IA, USA
}

\section{Edited by:}

Geoffrey A. Head, Baker IDI Heart and Diabetes Institute, Australia

Reviewed by:

Eugene Nalivaiko, University of

Newcastle, Australia

Angela J. Grippo, Northern Illinois

University, USA

Erica A. Wehrwein, Michigan State University, USA

\section{*Correspondence:}

Rasna Sabharwal, Department of Internal Medicine, University of lowa Carver College of Medicine, 607 MRC, lowa City, IA 52242, USA e-mail: rasna-sabharwal@uiowa.edu
Muscular dystrophy is a progressive disease of muscle weakness, muscle atrophy and cardiac dysfunction. Patients afflicted with muscular dystrophy exhibit autonomic dysfunction along with cognitive impairment, severe depression, sadness, and anxiety. Although the psychological aspects of cardiovascular disorders and stress disorders are well known, the physiological mechanism underlying this relationship is not well understood, particularly in muscular dystrophy. Therefore, the goal of this perspective is to highlight the importance of autonomic dysfunction and psychological stress disorders in the pathogenesis of muscular dystrophy. This article will for the first time-(i) outline autonomic mechanisms that are common to both psychological stress and cardiovascular disorders in muscular dystrophy; (ii) propose therapies that would improve behavioral and autonomic functions in muscular dystrophy.

Keywords: heart rate variability, sympathetic nervous system, parasympathetic nervous system, baroreceptor reflex, neuromuscular disease, depression, anxiety
Muscular dystrophy is a devastating neuromuscular disorder that is currently without an effective therapy. It is characterized by progressive increase in muscle weakness and muscle wasting. Myocardial disease, manifesting predominantly as dilated cardiomyopathy (DCM) and congestive heart failure or conduction system abnormalities have been observed in many muscular dystrophies. Evidence of an association between vulnerability to lethal arrhythmias and signs of either increased sympathetic or reduced parasympathetic tone as quantitative markers of autonomic activity in muscular dystrophy are becoming increasingly recognized in patients and animals (Groh, 2012; Russo et al., 2012).

The physical and social hardships associated with the disease often lead to psychological stress disorders such as depression and anxiety, in muscular dystrophy patients. Psychological stress affects both mental and physical health. Depressed patients with or without a history of cardiovascular pathology display signs such as elevated heart rate (HR), reduced HR variability (HRV), and increased physiological reactivity to environmental stressors which may cause predisposition to cardiovascular events. Converging evidence from experimental and epidemiological studies indicate that there is a bidirectional association between psychological stress and cardiac risk, such that presence of one increases the likelihood of developing the other (Penninx et al., 2001; Freedland et al., 2003; Johnson and Grippo, 2006). Although psychological stress disorders are prevalent in patients with muscular dystrophy, their physiological and pathophysiological consequences on disease progression have received little attention. The focus of this perspective is to demonstrate that synergistic actions of autonomic dysregulation and psychological stress may exacerbate disease progression in muscular dystrophy and identify strategies to yield better therapeutic outcomes.

\section{AUTONOMIC DYSREGULATION IN MUSCULAR DYSTROPHY}

Evidence of aberrant autonomic signaling has been demonstrated in both patients and animals with Duchenne, Becker, myotonic type 1 (DM1) muscular dystrophy. HRV, as a quantitative marker of parasympathetic tone, is decreased in muscular dystrophies (Politano et al., 2008; Inoue et al., 2009; Della Marca et al., 2010). It has been suggested that activation of the renin angiotensin system (RAS) contributes to the pathological changes occurring in muscular dystrophy (Cohn et al., 2007; Sun et al., 2009; Sabharwal et al., 2010a; Cabello-Verrugio et al., 2012). Previous work has provided evidence of autonomic dysregulation and loss of exercise-induced sympatholysis in muscular dystrophy (Sander et al., 2000). Furthermore, treatment of muscular dystrophy patients with angiotensin converting enzyme inhibitors (ACEi) and $\beta$-blockers has been shown to delay onset of DCM (Dubuc et al., 2005; Blain et al., 2013). These studies led us to determine the importance of autonomic dysregulation in pathogenesis of muscular dystrophy. We did so by utilizing an established mouse model of limb girdle muscular dystrophy (LGMD).

Dystrophin glycoprotein complex (DGC) is composed of multiple proteins that form a physical linkage between the intracellular and extracellular matrix. Sarcoglycans are important component of the DGC that protects cell membrane against forces generated during muscle contraction (Straub et al., 1998). Mutation in sarcoglycan delta (Sgcd) causes LGMD-2F. We found that young Sgcd deficient mice $\left(\mathrm{Sgcd}^{-/}\right)$exhibit severe autonomic dysregulation (reduced HRV, impaired baroreflex function, sympatho-vagal imbalance) before left ventricular (LV) dysfunction (Sabharwal et al., 2010b). Furthermore, we found that the severity of autonomic dysregulation in young $\mathrm{Sgcd}^{-/-}$ mice predicts severity of LV dysfunction and mortality at older ages (Sabharwal et al., 2010b). We speculate that the combined effects of chronic autonomic dysfunction and psychological stress 
provoke arrhythmias in muscular dystrophy; the latter has been recognized as a common cause of mortality in muscular dystrophy (Groh, 2012; Russo et al., 2012).

\section{PSYCHOLOGICAL STRESS IN MUSCULAR DYSTROPHY}

The association of intellectual impairment with Duchenne muscular dystrophy has long been recognized. Recent studies have demonstrated psychiatric disorders such as autism, dysthymic and clinical depression are fairly common in patients afflicted with DM1, Duchenne, LGMD, and facioscapulohumeral muscular dystrophies (Fitzpatrick et al., 1986; Douniol et al., 2009; Winblad et al., 2013). Children with muscular dystrophy not only face inevitable deterioration of physical functioning, but also become susceptible to emotional and behavioral problems, mental alteration mainly characterized by poor verbal Intelligence Quotient, memory, and cognitive deficits, and reading disabilities (Billard et al., 1992; Polakoff et al., 1998). These deficits are without histopathological abnormalities in the brain (Dubowitz and Crome, 1969; Billard et al., 1992). The $m d x$ mouse is a widely used experimental model of human Duchenne muscular dystrophy. In addition to skeletal muscle weakness and reduced locomotor activity, $m d x$ mice exhibit disruption in synaptic plasticity, reduced long-term potentiation in Purkinje cells, learning, and memory deficits along with enhanced anxiety-related and defensive freezing behavior (Anderson et al., 2004; Sekiguchi et al., 2009).

In DM1, heart conduction defects, endocrine dysfunction and brain abnormalities such as cerebral atrophy and white matter lesions are fairly common (Meola and Sansone, 2007). DM1 is associated with cognitive deficits, depression, anxiety, mood, and personality disorders (Meola and Sansone, 2007). Similarly, mice with deletion of muscleblind-like 1 (Mbnl1), a RNA splice regulator that causes DM1, exhibit cognitive impairment, learning, and memory deficits, and behavioral abnormalities (depression, autism, anxiety) (Matynia et al., 2012).

Peripartum cardiomyopathy is LV dysfunction that presents toward the end of pregnancy or in the months just after delivery. Women afflicted with muscular dystrophy and psychological stress disorders are at a greater risk to develop peripartum cardiomyopathy. Recently, two cases of postpartum cardiomyopathy have been reported in previously asymptomatic carriers of Duchenne muscular dystrophy (Davies et al., 2001; Cheng and Prior, 2013). Women with peripartum cardiomyopathy have reduced levels of signal transducer and activator of transcription 3 (STAT3), increased cathepsin D, and decreased expression of manganese superoxide dismutase; the combination of which causes apoptosis, impaired angiogenesis, and oxidative stress. Bromocriptine, that blocks the release of prolactin from the pituitary gland, has been reported to decrease morbidity and mortality in this condition (Sliwa et al., 2010), although this is yet to be confirmed.

Whilst physiological mechanisms of psychological stress are largely unknown, these association studies demonstrate high prevalence of stress disorders in muscular dystrophies. There is mounting evidence that psychological stress plays a critical role in triggering cardiac arrhythmias and sudden cardiac death.
Therefore, it becomes imperative to determine the underlying mechanisms of these dysfunctions.

\section{PROPOSED MECHANISMS OF AUTONOMIC DYSFUNCTION AND PSYCHOLOGICAL STRESS IN MUSCULAR DYSTROPHY}

Depression has been characterized by activation of the sympathetic nervous system and withdrawal of parasympathetic tone to the heart, increased resting HR and reduced HRV (Lahmeyer and Bellur, 1987; Barton et al., 2007). In humans, 24-h electrocardiogram provides a useful strategy for investigating autonomic consequences of depression and predictors of mortality (Aronow et al., 1996; Guzzetti et al., 2005). Cardiac norepinephrine spillover, activation of sympathetic nervous system and reduced neuronal reuptake of norepinephrine predispose to the development of cardiac arrhythmias in psychological disorders (Esler et al., 2004; Barton et al., 2007). Chronic stress can also evoke arrhythmias by altering stability of cardiac repolarization (Carney et al., 2003; Lampert et al., 2005). Lambert et al. suggest that the sympathetic neurons fire more often in multiple spike pattern in patients with panic disorders (Lambert et al., 2006).

Some of the reflexes that could be important in regulating sympathetic and parasympathetic outflow in muscular dystrophy are baroreceptor reflexes, skeletal muscle afferent reflex, and cardiac vagal afferent reflex (Figure 1). Baroreceptors are mechanosensitive nerve endings located in carotid sinuses and aortic arch that function as blood pressure sensors. Changes in baroreceptor activity evoke reflex changes in parasympathetic and sympathetic activity (Chapleau et al., 2001; Head and Mayorov, 2001; Stauss, 2002). Reduced baroreflex gain can contribute to cardiovascular morbidity and mortality via reduction in parasympathetic activity, an increase in sympathetic activity, or both. There are several reports whereby reduced baroreflex gain and depression increase the risk of ventricular fibrillation (Billman et al., 1982; Schwartz et al., 1988; Watkins and Grossman, 1999). Rats exposed to a series of chronic mild stressors exhibit anhedonia (an essential feature of human depression), reduced baroreflex function, elevated $\mathrm{HR}$, decreased HRV, and exaggerated pressor and HR responses to air jet stress (Grippo et al., 2002, 2008). Mechanoreceptors located in the heart and cardiopulmonary region sense changes in central blood volume through their sensitivity to cardiac and vascular distension. In heart failure or DCM (as seen in advanced stages of muscular dystrophy), the mechanosensitivity of cardiac vagal afferents is severely depressed which can contribute to an increase in sympathetic tone, decrease in parasympathetic tone, and fluid retention (Walgenbach and Shepherd, 1984; DiBona and Sawin, 1995). Another neural mechanism that is likely to be important in muscular dystrophy is the somatic afferent reflex. Group III and IV muscle afferents are activated by changes in $\mathrm{pH}$, inflammatory mediators, oxidative stress and/or by abnormal mechanical coupling between muscle and sensory nerve endings to evoke reflex increases in sympathetic activity, inhibition of parasympathetic activity, and decrease in baroreflex gain (Delliaux et al., 2009; Kaufman, 2012).

Stressful stimuli of different modalities activate sympathoadrenal and hypothalamic-pituitary (HPA) axes (Badoer, 2001). 


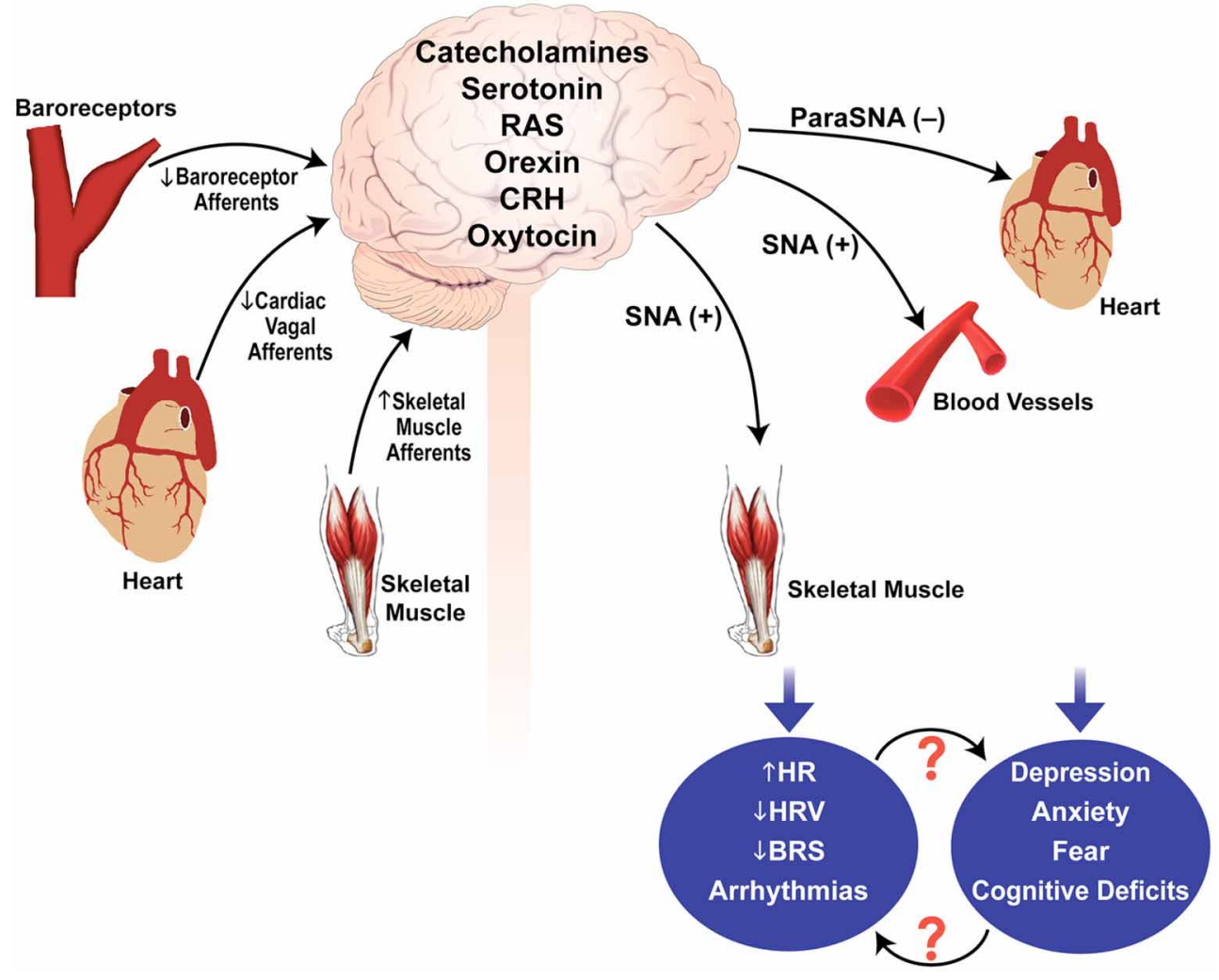

FIGURE 1 | Possible mechanisms involved in autonomic dysfunction and psychological stress in muscular dystrophy. Sensory input by the baroreceptor afferents, cardiac vagal afferents, and skeletal muscle afferents are integrated within the brain to modulate parasympathetic and sympathetic outflows. Disturbances in the sensory inputs and/or central integration and neurotransmission may contribute to autonomic dysregulation and psychological stress in muscular dystrophy. SNA, sympathetic nerve activity; ParaSNA, parasympathetic nerve activity; RAS, renin angiotensin system; $\mathrm{CRH}$, corticotrophin releasing hormone; $\mathrm{HRV}$, heart rate variability; $\mathrm{HR}$, heart rate; BRS, baroreflex sensitivity; (-), inhibition; (+), excitation.
It is now well established that the dorsomedial hypothalamus is a key area involved in integrating neurally-mediated cardiovascular responses to psychological stress. This area receives synaptic inputs from many regions of the brain that are activated during stress including periaqueductal gray, amygdala, raphe pallidus, rostroventral, and caudal portions of the lateral medulla, hippocampus, and the nucleus of the solitary tract (Cechetto and Chen, 1990; Hunt et al., 2010; Xavier et al., 2013). Some of the neurotransmitters involved in cardiovascular and behavioral responses to stress are serotonin, catecholamines, dopamine, histamine, oxytocin, vasopressin, angiotensin II, corticotrophin releasing hormone, the cytokines IL-1 $\beta$, and TNF- $\alpha$ etc. (Mayorov and Head, 2003; Wsol et al., 2008). It is noteworthy that several proteins belonging to the DGC and involved in muscular dystrophies (dystroglycans, dystrophin, sarcoglycans) have now been identified in forebrain, midbrain, and brainstem (Anastasi et al., 2012; Waite et al., 2012).

It is important to emphasize that mechanisms of autonomic dysfunction or psychological stress in muscular dystrophy are yet to be identified. Figure 1 thus provides a simplistic overview of possible pathways/mechanisms that may contribute to the pathogenesis of this disease.

\section{THERAPEUTIC TARGETS TO IMPROVE AUTONOMIC FUNCTION AND REDUCE PSYCHOLOGICAL STRESS}

The RAS is activated in muscular dystrophy (Sun et al., 2009; Sabharwal et al., 2010a; Cabello-Verrugio et al., 2012). RAS is comprised of two axes-vasoconstrictor angiotensin II (Ang II) acts primarily via Ang II type 1 receptors $\left(\mathrm{AT}_{1} \mathrm{R}\right)$ and the vasodilator Ang-(1-7) peptide acting on Mas receptors (Bader et al., 2012). Ang II also acts on type 2 receptors $\left(\mathrm{AT}_{2} \mathrm{R}\right)$. Angiotensin receptor blockers (ARBs) and ACEi are used clinically in muscular dystrophy and dilated cardiomyopathy (Dubuc et al., 2005; Cohn et al., 2007). It is well known that Ang II is a major stress hormone (DuboYang et al., 1993). ARBs and ACEi are also used in treating conditions like mood disorders, depression, and neurodegenerative and traumatic disorders of the brain (Bostwick, 2010). Systemic administration of candesartan/losartan can abrogate behavioral responses to acute and long-term isolation stress (Baiardi et al., 2004; Armando et al., 2007), cold restraint stress (Bregonzio et al., 2008), and forced swim test (Martin et al., 1990 ) in rodents. ARBs and ACEi have also been shown to be effective in reducing brain inflammation associated with depression (Young et al., 2003; Munoz et al., 2006). Psychological stress reduces expression of central $\mathrm{AT}_{2} \mathrm{R}$ receptors and animals lacking $\mathrm{AT}_{2} \mathrm{R}$ develop anxious behavior (Hein et al., 1995; Ichiki et al., 
1995). These studies suggest that centrally acting $\mathrm{AT}_{2} \mathrm{R}$ agonists may serve as potential anxiolytic agents. More recently, Ang(1-7) has also been suggested to exert anxiolytic actions. Bild et al demonstrated that rats treated with Ang-(1-7) performed better in the maze test than the untreated animals (Bild and Ciobica, 2013). Furthermore, mice lacking Mas receptors display increased anxiety (Walther et al., 1998), and activation of the Ang-(1-7)/Mas axis attenuates stress-induced tachycardia in rats (Martins Lima et al., 2013). These studies suggest that drugs targeting the RAS [Ang-(1-7)/Mas, $\mathrm{AT}_{2} \mathrm{R}$ agonists, $\mathrm{ACEi}$, or ARBs] may improve outcomes in muscular dystrophy not only through their direct autonomic/cardiovascular effects but also via their anxiolytic actions.

Serotonin (5-hydroxytryptamine, 5-HT) is a neurotransmitter that modulates stress responses by interacting with the HPA axis and sympathetic nervous system (Chrousos, 2009). Selective serotonin reuptake inhibitors (SSRI) and serotonin norepinephrine reuptake inhibitors (SNRI) are used for treatment of depression and anxiety (Glassman et al., 2002; Trivedi et al., 2006). SSRIs exert their effects via modulating monoaminergic signaling or via their anti-inflammatory actions (Walker, 2013). SSRIs are considered safe even when administered to patients with serious cardiovascular diseases (Glassman et al., 2002; Taylor et al., 2005). SSRIs reduce depressive symptoms, increase HRV, reduce inflammatory markers, normalize urinary cortical excretion, and reduce plasma catecholamine levels (Glassman et al., 2002). Loss of central 5-HT neurons may cause hypersomnia in patients with myotonic dystrophy (Ono et al., 1998). SSRI therapy can also revert abnormal electromyogram in myotonic dystrophy type 1 (Chisari et al., 2009), and improve psychiatric comorbidities in Becker muscular dystrophy (Chaichana et al., 2007). Thus, SSRI therapy may improve outcomes in muscular dystrophy via multiple mechanisms.

\section{SUMMARY}

Muscular dystrophy is a catastrophic disease which is characterized by progressive muscle weakness and wasting, cardiomyopathy, and early mortality. Patients with muscular dystrophy are commonly afflicted with psychological disorders like depression, anxiety, cognitive deficits etc., which likely exacerbates disease progression and worsens the quality of life. Both muscular dystrophy and behavioral disorders are associated with autonomic dysregulation. In view of the devastating outcome of muscular dystrophy most attention has been directed toward improving muscle function and structure. However, treating both autonomic dysregulation and stress disorders is recommended for patients with muscular dystrophy. Additive and synergistic actions are likely to result in better therapeutic outcomes.

\section{ACKNOWLEDGMENTS}

The author acknowledges critical reading of the article by Dr. Mark W. Chapleau (University of Iowa), and Ms. Teresa Ruggle (Design Center, University of Iowa) who provided assistance in preparing the figure.

\section{REFERENCES}

Anastasi, G., Tomasello, F., Di Mauro, D., Cutroneo, G., Favaloro, A., Conti, A., et al. (2012). Expression of sarcoglycans in the human cerebral cortex: an immunohistochemical and molecular study. Cells Tissues Organs 196, 470-480. doi: $10.1159 / 000336842$

Anderson, J. L., Head, S. I., and Morley, J. W. (2004). Long-term depression is reduced in cerebellar Purkinje cells of dystrophin-deficient mdx mice. Brain Res. 1019, 289-292. doi: 10.1016/j.brainres.2004.06.011

Armando, I., Volpi, S., Aguilera, G., and Saavedra, J. M. (2007). Angiotensin II AT1 receptor blockade prevents the hypothalamic corticotropinreleasing factor response to isolation stress. Brain Res. 1142, 92-99. doi: 10.1016/j.brainres.2007.01.037

Aronow, W. S., Ahn, C., Mercando, A. D., and Epstein, S. (1996). Association of average heart rate on 24-hour ambulatory electrocardiograms with incidence of new coronary events at 48-month follow-up in 1,311 patients (mean age 81 years) with heart disease and sinus rhythm. Am. J. Cardiol. 78, 1175-1176.

Bader, M., Santos, R. A., Unger, T., and Steckelings, U. M. (2012). New therapeutic pathways in the RAS. J. Renin Angiotensin Aldosterone Syst. 13, 505-508. doi: $10.1177 / 1470320312466519$

Badoer, E. (2001). Hypothalamic paraventricular nucleus and cardiovascular regulation. Clin. Exp. Pharmacol. Physiol. 28, 95-99. doi: 10.1046/j.14401681.2001.03413.x

Baiardi, G., Bregonzio, C., Jezova, M., Armando, I., and Saavedra, J. M. (2004). Angiotensin II AT1 receptor blockade prolongs the lifespan of spontaneously hypertensive rats and reduces stress-induced release of catecholamines, glucocorticoids, and vasopressin. Ann. N.Y. Acad. Sci. 1018, 131-136. doi: 10.1196/annals.1296.015

Barton, D. A., Dawood, T., Lambert, E. A., Esler, M. D., Haikerwal, D., Brenchley, C., et al. (2007). Sympathetic activity in major depressive disorder: identifying those at increased cardiac risk? J. Hypertens. 25, 2117-2124. doi: 10.1097/HJH.0b013e32829baae7

Bild, W., and Ciobica, A. (2013). Angiotensin-(1-7) central administration induces anxiolytic-like effects in elevated plus maze and decreased oxidative stress in the amygdala. J. Affect. Disord. 145, 165-171. doi: 10.1016/j.jad.2012.07.024

Billard, C., Gillet, P., Signoret, J. L., Uicaut, E., Bertrand, P., Fardeau, M., et al. (1992). Cognitive functions in Duchenne muscular dystrophy: a reappraisal and comparison with spinal muscular atrophy. Neuromuscul. Disord. 2, 371-378. doi: 10.1016/S0960-8966(06)80008-8

Billman, G. E., Schwartz, P. J., and Stone, H. L. (1982). Baroreceptor reflex control of heart rate: a predictor of sudden cardiac death. Circulation 66, 874-880. doi: 10.1161/01.CIR.66.4.874

Blain, A., Greally, E., Laval, S., Blamire, A., Straub, V., and MacGowan, G. A. (2013). Beta-blockers, left and right ventricular function, and in-vivo calcium influx in muscular dystrophy cardiomyopathy. PLoS ONE 8:e57260. doi: 10.1371/journal.pone.0057260

Bostwick, J. M. (2010). A generalist's guide to treating patients with depression with an emphasis on using side effects to tailor antidepressant therapy. Mayo Clin. Proc. 85, 538-550. doi: 10.4065/mcp.2009.0565

Bregonzio, C., Seltzer, A., Armando, I., Pavel, J., and Saavedra, J. M. (2008) Angiotensin II AT(1) receptor blockade selectively enhances brain AT(2) receptor expression, and abolishes the cold-restraint stress-induced increase in tyrosine hydroxylase mRNA in the locus coeruleus of spontaneously hypertensive rats. Stress 11, 457-466. doi: 10.1080/10253890801892040

Cabello-Verrugio, C., Morales, M. G., Cabrera, D., Vio, C. P., and Brandan, E. (2012). Angiotensin II receptor type 1 blockade decreases CTGF/CCN2mediated damage and fibrosis in normal and dystrophic skeletal muscles. J. Cell. Mol. Med. 16, 752-764. doi: 10.1111/j.1582-4934.2011.01354.x

Carney, R. M., Freedland, K. E., Stein, P. K., Watkins, L. L., Catellier, D., Jaffe, A. S., et al. (2003). Effects of depression on QT interval variability after myocardial infarction. Psychosom. Med. 65, 177-180. doi: 10.1097/01.PSY.0000033129.21715.4B

Cechetto, D. F., and Chen, S. J. (1990). Subcortical sites mediating sympathetic responses from insular cortex in rats. Am. J. Physiol. 258, R245-R255.

Chaichana, K. L., Buffington, A. L., Brandes, M., Edwin, D., and Lee, H. B. (2007). Treatment of psychiatric comorbidities in a patient with becker muscular dystrophy. Psychosomatics 48, 167-169. doi: 10.1176/appi.psy.48.2.167

Chapleau, M. W., Li, Z., Meyrelles, S. S., Ma, X., and Abboud, F. M. (2001). Mechanisms determining sensitivity of baroreceptor afferents in health and disease. Ann. N.Y. Acad. Sci. 940, 1-19. doi: 10.1111/j.1749-6632.2001.tb 03662.x

Cheng, V. E., and Prior, D. L. (2013). Peripartum cardiomyopathy in a previously asymptomatic carrier of duchenne muscular dystrophy. Heart Lung Circ. 22, 677-681. doi: 10.1016/j.hlc.2012.11.015 
Chisari, C., Licitra, R., Pellegrini, M., Pellegrino, M., and Rossi, B. (2009). Fluoxetine blocks myotonic runs and reverts abnormal surface electromyogram pattern in patients with myotonic dystrophy type 1. Clin. Neuropharmacol. 32, 330-334. doi: 10.1097/WNF.0b013e3181ae5546

Chrousos, G. P. (2009). Stress and disorders of the stress system. Nat. Rev. Endocrinol. 5, 374-381. doi: 10.1038/nrendo.2009.106

Cohn, R. D., van Erp, C., Habashi, J. P., Soleimani, A. A., Klein, E. C., Lisi, M. T., et al. (2007). Angiotensin II type 1 receptor blockade attenuates TGF-betainduced failure of muscle regeneration in multiple myopathic states. Nat. Med. 13, 204-210. doi: 10.1038/nm1536

Davies, J. E., Winokur, T. S., Aaron, M. F., Benza, R. L., Foley, B. A., and Holman W. L. (2001). Cardiomyopathy in a carrier of Duchenne's muscular dystrophy. J. Heart Lung Transplant. 20, 781-784. doi: 10.1016/S1053-2498(00)00240-0

Della Marca, G., Frusciante, R., Scatena, M., Dittoni, S., Testani, E., Vollono, C., et al. (2010). Heart rate variability in facioscapulohumeral muscular dystrophy. Funct. Neurol. 25, 211-216.

Delliaux, S., Brerro-Saby, C., Steinberg, J. G., and Jammes, Y. (2009). Reactive oxygen species activate the group IV muscle afferents in resting and exercising muscle in rats. Pflugers Arch. 459, 143-150. doi: 10.1007/s00424-009-0713-8

DiBona, G. F., and Sawin, L. L. (1995). Increased renal nerve activity in cardiac failure: arterial vs. cardiac baroreflex impairment. Am. J. Physiol. 268, R112-R116.

Douniol, M., Jacquette, A., Guile, J. M., Tanguy, M. L., Angeard, N., Heron, D., et al. (2009). Psychiatric and cognitive phenotype in children and adolescents with myotonic dystrophy. Eur. Child Adolesc. Psychiatry 18, 705-715. doi: 10.1007/s00787-009-0037-4

Dubowitz, V., and Crome, L. (1969). The central nervous system in Duchenne muscular dystrophy. Brain 92, 805-808. doi: 10.1093/brain/92.4.805

DuboYang, G., Xi, Z. X., Wan, Y., Wang, H., and Bi, G. (1993). Changes in circulating and tissue angiotensin II during acute and chronic stress. Biol. Signals 2, 166-172. doi: 10.1159/000109488

Dubuc, D., Meune, C., Lerebours, G., Devaux, J. Y., Vaksmann, G., and Becane, H. M. (2005). Effect of perindopril on the onset and progression of left ventricular dysfunction in Duchenne muscular dystrophy. J. Am. Coll. Cardiol. 45, 855-857. doi: 10.1016/j.jacc.2004.09.078

Esler, M., Alvarenga, M., Lambert, G., Kaye, D., Hastings, J., Jennings, G., et al. (2004). Cardiac sympathetic nerve biology and brain monoamine turnover in panic disorder. Ann. N.Y. Acad. Sci. 1018, 505-514. doi: 10.1196/annals.1296.062

Fitzpatrick, C., Barry, C., and Garvey, C. (1986). Psychiatric disorder among boys with Duchenne muscular dystrophy. Dev. Med. Child Neurol. 28, 589-595. doi: 10.1111/j.1469-8749.1986.tb03900.x

Freedland, K. E., Rich, M. W., Skala, J. A., Carney, R. M., Davila-Roman, V. G., and Jaffe, A. S. (2003). Prevalence of depression in hospitalized patients with congestive heart failure. Psychosom. Med. 65, 119-128. doi: 10.1097/01.PSY.0000038938.67401.85

Glassman, A. H., O’Connor, C. M., Califf, R. M., Swedberg, K., Schwartz, P., Bigger J. T., et al. (2002). Sertraline treatment of major depression in patients with acute MI or unstable angina. JAMA 288, 701-709. doi: 10.1001/jama.288.6.701

Grippo, A. J., Moffitt, J. A., and Johnson, A. K. (2002). Cardiovascular alterations and autonomic imbalance in an experimental model of depression. Am. J. Physiol. Regul. Integr. Comp. Physiol. 282, R1333-R1341.

Grippo, A. J., Moffitt, J. A., and Johnson, A. K. (2008). Evaluation of baroreceptor reflex function in the chronic mild stress rodent model of depression. Psychosom. Med. 70, 435-443. doi: 10.1097/PSY.0b013e31816ff7dd

Groh, W. J. (2012). Arrhythmias in the muscular dystrophies. Heart Rhythm 9, 1890-1895. doi: 10.1016/j.hrthm.2012.06.038

Guzzetti, S., La Rovere, M. T., Pinna, G. D., Maestri, R., Borroni, E., Porta, A., et al. (2005). Different spectral components of $24 \mathrm{~h}$ heart rate variability are related to different modes of death in chronic heart failure. Eur. Heart J. 26, 357-362. doi: 10.1093/eurheartj/ehi067

Head, G. A., and Mayorov, D. N. (2001). Central angiotensin and baroreceptor control of circulation. Ann. N.Y. Acad. Sci. 940, 361-379. doi: 10.1111/j.17496632.2001.tb03691.x

Hein, L., Barsh, G. S., Pratt, R. E., Dzau, V. J., and Kobilka, B. K. (1995). Behavioura and cardiovascular effects of disrupting the angiotensin II type-2 receptor in mice. Nature 377, 744-747. doi: 10.1038/377744a0

Hunt, J. L., Zaretsky, D. V., Sarkar, S., and Dimicco, J. A. (2010). Dorsomedial hypothalamus mediates autonomic, neuroendocrine, and locomotor responses evoked from the medial preoptic area. Am. J. Physiol. Regul. Integr. Comp. Physiol. 298, R130-R140. doi: 10.1152/ajpregu.00574.2009

Ichiki, T., Labosky, P. A., Shiota, C., Okuyama, S., Imagawa, Y., Fogo, A., et al. (1995). Effects on blood pressure and exploratory behaviour of mice lacking angiotensin II type-2 receptor. Nature 377, 748-750. doi: 10.1038/377748a0

Inoue, M., Mori, K., Hayabuchi, Y., Tatara, K., and Kagami, S. (2009). Autonomic function in patients with Duchenne muscular dystrophy. Pediatr. Int. 51, 33-40. doi: 10.1111/j.1442-200X.2008.02656.x

Johnson, A. K., and Grippo, A. J. (2006). Sadness and broken hearts: neurohumoral mechanisms and co-morbidity of ischemic heart disease and psychological depression. J. Physiol. Pharmacol. 57(Suppl. 11), 5-29.

Kaufman, M. P. (2012). The exercise pressor reflex in animals. Exp. Physiol. 97, 51-58. doi: 10.1113/expphysiol.2011.057539

Lahmeyer, H. W., and Bellur, S. N. (1987). Cardiac regulation and depression. J. Psychiatr. Res. 21, 1-6. doi: 10.1016/0022-3956(87)90004-5

Lambert, E., Hotchkin, E., Alvarenga, M., Pier, C., Richards, J., Barton, D., et al. (2006). Single-unit analysis of sympathetic nervous discharges in patients with panic disorder. J. Physiol. 570, 637-643. doi: 10.1113/jphysiol.2005.100040

Lampert, R., Shusterman, V., Burg, M. M., Lee, F. A., Earley, C., Goldberg, A., et al. (2005). Effects of psychologic stress on repolarization and relationship to autonomic and hemodynamic factors. J. Cardiovasc. Electrophysiol. 16, 372-377. doi: 10.1046/j.1540-8167.2005.40580.x

Martin, P., Massol, J., and Puech, A. J. (1990). Captopril as an antidepressant? Effects on the learned helplessness paradigm in rats. Biol. Psychiatry 27, 968-974. doi: 10.1016/0006-3223(90)90034-Y

Martins Lima, A., Xavier, C. H., Ferreira, A. J., Raizada, M. K., Wallukat, G., Santos, R. A., et al. (2013). Activation of angiotensin-converting enzyme 2/Angiotensin(1-7)/Mas axis attenuates the cardiac reactivity to acute emotional stress. Am. J. Physiol. Heart. Circ. Physiol. 305, H1057-H1067. doi: 10.1152/ajpheart.00433. 2013

Matynia, A., Ng, C. H., Dansithong, W., Chiang, A., Silva, A. J., and Reddy, S. (2012). Muscleblind1, but not Dmpk or Six5, contributes to a complex phenotype of muscular and motivational deficits in mouse models of myotonic dystrophy. PLoS ONE 5:e9857. doi: 10.1371/journal.pone.0009857

Mayorov, D. N., and Head, G. A. (2003). AT1 receptors in the RVLM mediate pressor responses to emotional stress in rabbits. Hypertension 41, 1168-1173. doi: 10.1161/01.HYP.0000064574.29317.45

Meola, G., and Sansone, V. (2007). Cerebral involvement in myotonic dystrophies. Muscle Nerve 36, 294-306. doi: 10.1002/mus.20800

Munoz, A., Rey, P., Guerra, M. J., Mendez-Alvarez, E., Soto-Otero, R., and Labandeira-Garcia, J. L. (2006). Reduction of dopaminergic degeneration and oxidative stress by inhibition of angiotensin converting enzyme in a MPTP model of parkinsonism. Neuropharmacology 51, 112-120. doi: 10.1016/j.neuropharm.2006.03.004

Ono, S., Takahashi, K., Jinnai, K., Kanda, F., Fukuoka, Y., Kurisaki, H., et al. (1998). Loss of serotonin-containing neurons in the raphe of patients with myotonic dystrophy: a quantitative immunohistochemical study and relation to hypersomnia. Neurology 50, 535-538. doi: 10.1212/WNL.50.2.535

Penninx, B. W., Beekman, A. T., Honig, A., Deeg, D. J., Schoevers, R. A., van Eijk, J. T., et al. (2001). Depression and cardiac mortality: results from a community-based longitudinal study. Arch. Gen. Psychiatry 58, 221-227. doi: 10.1001/archpsyc.58.3.221

Polakoff, R. J., Morton, A. A., Koch, K. D., and Rios, C. M. (1998). The psychosocial and cognitive impact of Duchenne's muscular dystrophy. Semin. Pediatr. Neurol. 5, 116-123. doi: 10.1016/S1071-9091(98)80027-2

Politano, L., Palladino, A., Nigro, G., Scutifero, M., and Cozza, V. (2008). Usefulness of heart rate variability as a predictor of sudden cardiac death in muscular dystrophies. Acta Myol. 27, 114-122.

Russo, V., Rago, A., Politano, L., Papa, A. A., Di Meo, F., Russo, M. G., et al. (2012). Increased dispersion of ventricular repolarization in Emery Dreifuss muscular dystrophy patients. Med. Sci. Monit. 18, CR643-CR647. doi: 10.12659/MSM.883541

Sabharwal, R., Weiss, R. M., Zimmerman, K., and Chapleau, M. W. (2010a) Angiotensin II contributes to skeletal muscle fibrosis, reduced locomotor activity and autonomic dysfunction in $\delta$-sarcoglycan deficient mice with muscular dystrophy. Hypertension (abstract) 56, E103.

Sabharwal, R., Weiss, R. M., and Chapleau, M. W. (2010b). Dysautonomia precedes cardiomyopathy in a mouse model of muscular dystrophy. Clin. Auton Res. (abstract) 20, 51-52. 
Sander, M., Chavoshan, B., Harris, S. A., Iannaccone, S. T., Stull, J. T., Thomas, G. D., et al. (2000). Functional muscle ischemia in neuronal nitric oxide synthasedeficient skeletal muscle of children with Duchenne muscular dystrophy. Proc. Natl. Acad. Sci. U.S.A. 97, 13818-13823. doi: 10.1073/pnas.250379497

Schwartz, P. J., Vanoli, E., Stramba-Badiale, M., De Ferrari, G. M., Billman, G. E., and Foreman, R. D. (1988). Autonomic mechanisms and sudden death. New insights from analysis of baroreceptor reflexes in conscious dogs with and without a myocardial infarction. Circulation 78, 969-979. doi: 10.1161/01.CIR.78.4.969

Sekiguchi, M., Zushida, K., Yoshida, M., Maekawa, M., Kamichi, S., Sahara, Y., et al. (2009). A deficit of brain dystrophin impairs specific amygdala GABAergic transmission and enhances defensive behaviour in mice. Brain 132, 124-135. doi: 10.1093/brain/awn253

Sliwa, K., Blauwet, L., Tibazarwa, K., Libhaber, E., Smedema, J. P., Becker, A., et al. (2010). Evaluation of bromocriptine in the treatment of acute severe peripartum cardiomyopathy: a proof-of-concept pilot study. Circulation 121, 1465-1473. doi: 10.1161/CIRCULATIONAHA.109.901496

Stauss, H. M. (2002). Baroreceptor reflex function. Am. J. Physiol. Regul. Integr. Comp. Physiol. 283, R284-R286.

Straub, V., Duclos, F., Venzke, D. P., Lee, J. C., Cutshall, S., Leveille, C. J., et al. (1998). Molecular pathogenesis of muscle degeneration in the delta-sarcoglycan-deficient hamster. Am. J. Pathol. 153, 1623-1630. doi: 10.1016/S0002-9440(10)65751-3

Sun, G., Haginoya, K., Dai, H., Chiba, Y., Uematsu, M., Hino-Fukuyo, N., et al. (2009). Intramuscular renin-angiotensin system is activated in human muscular dystrophy. J. Neurol. Sci. 280, 40-48. doi: 10.1016/j.jns.2009.01.020

Taylor, C. B., Youngblood, M. E., Catellier, D., Veith, R. C., Carney, R. M., Burg, M. M., et al. (2005). Effects of antidepressant medication on morbidity and mortality in depressed patients after myocardial infarction. Arch. Gen. Psychiatry 62, 792-798. doi: 10.1001/archpsyc.62.7.792

Trivedi, M. H., Rush, A. J., Wisniewski, S. R., Nierenberg, A. A., Warden, D., Ritz, L., et al. (2006). Evaluation of outcomes with citalopram for depression using measurement-based care in STAR*D: implications for clinical practice. Am. J. Psychiatry 163, 28-40. doi: 10.1176/appi.ajp.163.1.28

Waite, A., Brown, S. C., and Blake, D. J. (2012). The dystrophin-glycoprotein complex in brain development and disease. Trends Neurosci. 35, 487-496. doi: 10.1016/j.tins.2012.04.004

Walgenbach, S. C., and Shepherd, J. T. (1984). Role of arterial and cardiopulmonary mechanoreceptors in the regulation of arterial pressure during rest and exercise in conscious dogs. Mayo Clin. Proc. 59, 467-475. doi: 10.1016/S0025$6196(12) 60435-2$
Walker, F. R. (2013). A critical review of the mechanism of action for the selective serotonin reuptake inhibitors: do these drugs possess antiinflammatory properties and how relevant is this in the treatment of depression? Neuropharmacology 67, 304-317. doi: 10.1016/j.neuropharm.2012.10.002

Walther, T., Balschun, D., Voigt, J. P., Fink, H., Zuschratter, W., Birchmeier, C., et al. (1998). Sustained long term potentiation and anxiety in mice lacking the Mas protooncogene. J. Biol. Chem. 273, 11867-11873. doi: 10.1074/jbc.273.19. 11867

Watkins, L. L., and Grossman, P. (1999). Association of depressive symptoms with reduced baroreflex cardiac control in coronary artery disease. Am. Heart J. 137, 453-457. doi: 10.1016/S0002-8703(99)70491-6

Winblad, S., Jensen, C., Mansson, J. E., Samuelsson, L., and Lindberg, C. (2013). Depression in Myotonic Dystrophy type 1: clinical and neuronal correlates. Behav. Brain Funct. 6, 25. doi: 10.1186/1744-9081-6-25

Wsol, A., Cudnoch-Jedrzejewska, A., Szczepanska-Sadowska, E., Kowalewski, S., and Puchalska, L. (2008). Oxytocin in the cardiovascular responses to stress. J. Physiol. Pharmacol. 59(Suppl. 8), 123-127.

Xavier, C. H., Beig, M. I., Ianzer, D., Fontes, M. A., and Nalivaiko, E. (2013). Asymmetry in the control of cardiac performance by dorsomedial hypothalamus. Am. J. Physiol. Regul. Integr. Comp. Physiol. 304, R664-R674. doi: 10.1152/ajpregu.00401.2012

Young, E. A., Lopez, J. F., Murphy-Weinberg, V., Watson, S. J., and Akil, H. (2003). Mineralocorticoid receptor function in major depression. Arch. Gen. Psychiatry 60, 24-28. doi: 10.1001/archpsyc.60.1.24

Conflict of Interest Statement: The author declares that the research was conducted in the absence of any commercial or financial relationships that could be construed as a potential conflict of interest.

Received: 10 September 2013; accepted: 12 January 2014; published online: 29 January 2014.

Citation: Sabharwal $R$ (2014) The link between stress disorders and autonomic dysfunction in muscular dystrophy. Front. Physiol. 5:25. doi: 10.3389/fphys.2014.00025 This article was submitted to Integrative Physiology, a section of the journal Frontiers in Physiology.

Copyright (c) 2014 Sabharwal. This is an open-access article distributed under the terms of the Creative Commons Attribution License (CC BY). The use, distribution or reproduction in other forums is permitted, provided the original author(s) or licensor are credited and that the original publication in this journal is cited, in accordance with accepted academic practice. No use, distribution or reproduction is permitted which does not comply with these terms. 